\title{
Biosynthesis characterization of silver nanoparticles using Cassia roxburghii DC. aqueous extract, and coated on cotton cloth for effective antibacterial activity
}

\author{
This article was published in the following Dove Press journal: \\ International Journal of Nanomedicine \\ I October 2015 \\ Number of times this article has been viewed
}

\section{Pannerselvam \\ Balashanmugam \\ Pudupalayam Thangavelu \\ Kalaichelvan \\ Centre for Advanced Studies in Botany, University of Madras, Chennai, India}

\begin{abstract}
The present study reports the green synthesis of silver nanoparticles (AgNPs) from silver precursor using a plant biomaterial, Cassia roxburghii DC., aqueous extract. The AgNPs were synthesized from the shade-dried leaf extract and assessed for their stability; they elucidated characteristics under UV-visible spectroscopy, X-ray diffraction, Fourier transform infrared spectroscopy, high-resolution transmission electron microscopy, and energy dispersive X-ray spectroscopy. The synthesized AgNPs exhibited a maximum absorption at $430 \mathrm{~nm}$, and the X-ray diffraction patterns showed that they were crystal in nature. Fourier transform infrared spectroscopy analysis confirmed the conversion of $\mathrm{Ag}^{+}$ions to AgNPs due to the reduction by capping material of plant extract. The HR-TEM analysis revealed that they are spherical ranging from $10 \mathrm{~nm}$ to $30 \mathrm{~nm}$. The spot EDAX analysis showed the presence of silver atoms. In addition, AgNPs were evaluated for their antibacterial activity against six different pathogenic bacteria: three Gram-positive bacteria, Bacillus subtilis, Staphylococcus aureus, and Micrococcus luteus, and three Gram-negative bacteria, Pseudomonas aeruginosa, Escherichia coli, and Enterobacter aerogenes. They were highly sensitive to AgNPs, whereas less sensitive to $\mathrm{AgNO}_{3}$. Furthermore, the green synthesized AgNPs were immobilized on cotton fabrics and screened for antibacterial activity. The immobilized AgNPs on cotton cloth showed high antibacterial activity. Therefore, they could be a feasible alternative source in treating wounds or may help in replacing pharmaceutical band-aids.
\end{abstract}

Keywords: bioreduction, stability, immobilization, cotton cloth, minimum inhibitory concentration

\section{Introduction}

Nanomaterials are at the leading edge of the rapidly developing field in nanotechnology. Their unique size makes them superior and indispensible in many areas of human activity. Nanotechnology encompasses the production and application of physical, chemical, and biological systems at scales ranging from individual atoms or molecules to submicron dimensions, as well as the integration of the resulting nanostructures into larger systems. Science and technology research in nanotechnology promises breakthroughs in areas such as materials and manufacturing, nanoelectronics, medicine and health care, energy, biotechnology, and information technology. Nanoparticles are usually referred to as the particles with a maximum size of $100 \mathrm{~nm}$. Nanoparticles exhibit new properties when compared to larger particles of the bulk material. The novel properties are derived due to the variations in specific characteristics, such as size, distribution, and morphology of particles. The nanoparticles have a wide range of applications, such as in combating microbes, drug delivery, catalysis, ${ }^{1}$ water purification, ${ }^{2}$ treatment
Correspondence: Pannerselvam Balashanmugam

Centre for Advanced Studies in Botany, University of Madras, Guindy Campus,

Chennai 600 025, India

Tel +9l 9994633730

Email biobala17@gmail.com
International Journal of Nanomedicine 2015:10 (Suppl I: Challenges in biomaterials research) 87-97 87 (c) (i) (5) 2015 Balashanmugam and Kalaichelvan. This work is published by Dove Medical Press Limited, and licensed under Creative Commons Attribution - Non Commercial (unported, v3.0) License. The full terms of the License are available at http://creativecommons.org/licenses/by-nc/3.0/. Non-commercial uses of the work are permitted without any further permissin how to request permission may be found at: http://www.dovepress.com/permissions.php 
of environmental waste, ${ }^{3}$ food industry, ${ }^{4,5}$ textile industry, ${ }^{6,7}$ biolabeling, and treatment of cancer.

Generally, metal nanoparticles can be prepared and stabilized by physical and chemical methods. The chemical approaches, such as chemical reduction, electrochemical techniques, lithography, and photochemical reduction, are most widely used. ${ }^{8,9}$ Though they have the control over the size and shape of the nanoparticles, they pose some threats when they are being used in the medical applications. Moreover, they are expensive, need high pressure, energy, and temperature, and need use of some toxic chemicals for the stabilization of nanoparticles, leading to adverse effects when they are being applied in the medical and pharmaceutical applications $;{ }^{10}$ hence, there is an increasing need for the development of an eco-friendly process for the synthesis of nanoparticles. Plants have attracted more attention than the bacteria and fungi as they are easily available and do not require the maintenance of highly aseptic conditions. ${ }^{11}$ Among the noble metal nanoparticles, silver nanoparticles (AgNPs) are considered to be of great importance because of their high antiviral, ${ }^{12}$ antibacterial, and antifungal properties ${ }^{13}$ and good electrical conductivity, chemical stability, and catalytic activity.

Though there is a widespread use of AgNPs in the medical, cosmetics, and pharmaceutical industries, there is a threat, as to the release of nanoparticles into the environment and their interaction with the biotic components of the ecosystem. ${ }^{14}$ Different sizes and shapes of the nanoparticles could pose a threat to human and environmental health. ${ }^{15}$ Hence, proper knowledge of the engineered nanomaterials, their mode of interaction, uptake, accumulation, and impact on the biosystems at various levels is inevitable to implement proper control to avoid nanopollution turning out to be a serious ecological concern. ${ }^{16,17}$ Recently, it has been shown that different sizes of AgNPs (20-80 nm) were toxic to thale cress (Arabidopsis thaliana) seedlings and they caused stunted growth even at very low concentration. Hence, it is assumed that the toxicity induced by the AgNPs on the plant system might be due to the presence of the toxic compounds present on the surface of the nanoparticles. ${ }^{18,19}$ Cassia roxburghii DC. is a graceful tree with spreading, drooping branches appearing to be overweighted by its wealth of clustering orange-red blossoms. C. roxburghii is native to Sri Lanka and Southern India. Cassia species are widely used in folk medicine for their laxative, purgative uses, and for treating skin diseases, such as ring worm, scabies, eczema, and wounds. C. roxburghii had been used in ethnomedicine for various liver disorders for its hepatoprotective activity. ${ }^{20}$ It is also being used in in vivo wound healing. ${ }^{21}$ In the present study, AgNPs were synthesized from C. roxburghii. They were characterized using high-resolution transmission electron microscopy, energy dispersive X-ray (EDX) spectroscopy, Fourier transform infrared spectroscopy (FTIR), and X-ray diffraction (XRD) analysis. The antibacterial activity of AgNPs and AgNPs coated on cotton fabric was investigated against six different pathogenic bacteria.

\section{Materials and methods}

All the analytical grade chemicals were purchased from Sigma-Aldrich Co. (St Louis, MO, USA). Silver nitrate was purchased from HiMedia Laboratories (Mumbai, India). The bacteria were obtained from the Culture Collection Facility at the Centre for Advanced Studies in Botany, University of Madras, Chennai.

\section{Collection of plant materials}

The healthy leaves of $C$. roxburghii were collected in and around Guindy campus, University of Madras, Chennai, during January 2012. They were washed twice with tap water and then rinsed with distilled water, removing dust particles from their surface. Then the leaves were shade dried for 3 days at room temperature.

\section{Preparation of the plant extract}

The air-dried leaves were ground to coarse powder using a blender; $4.0 \mathrm{~g}$ of the dried leaf powder sample was taken and mixed with $100 \mathrm{~mL}$ of glass distilled water. This mixture was kept at $55^{\circ} \mathrm{C}$ for 15 minutes in a water bath and cooled to room temperature and filtered through Whatman No 1 filter paper. This aqueous extract was refrigerated and used for further experiments.

\section{Synthesis of AgNPs}

A total of $1 \mathrm{~mL}$ of the C. roxburghii leaf aqueous extract was added to $9 \mathrm{~mL}$ of $1 \mathrm{mM}$ solution of silver nitrate in a $15 \mathrm{~mL}$ test tube. The reaction was performed in dark at room temperature overnight to minimize photoactivation of silver nitrate. The aqueous leaf extracts of C. roxburghii and $\mathrm{AgNO}_{3}$ solution were used as control. After the desired reaction period, the solution containing the AgNPs was centrifuged at 15,000 rpm for 10 minutes. The pellet was collected and redispersed in glass-distilled water, removing any interactive biological molecules. This was repeated thrice to ensure better separation of the AgNPs and was used for characterization studies. 


\section{Characterization of AgNPs}

UV-visible spectroscopy

The formation of dark brown color during the synthesis was confirmed as the formation of AgNPs. The reduction of the pure AgNPs was recorded under UV-visible spectroscopy using Hitachi U-2900 UV-visible spectrophotometer between $300 \mathrm{~nm}$ and $700 \mathrm{~nm}$. The UV-visible spectra of the plant leaf extract and silver nitrate solution were also recorded.

\section{Stability of AgNPs}

Time

The stability of AgNPs from C. roxburghii was recorded between $300 \mathrm{~nm}$ and $700 \mathrm{~nm}$ at different time intervals such as 0 hour, 6 hours, 12 hours, 18 hours, and 24 hours to 2 months. The absorbance of the solutions was measured using Hitachi U-2900 UV-visible spectrophotometer.

\section{HR-TEM and EDX}

A drop of AgNPs was placed on carbon-coated copper grids and allowed to stand for 2 minutes, and the excess solution was removed using a blotting paper allowed to dry at room temperature. High-resolution transmission electron microscopy observations were made on a FEI-TECNAI G2 T-30, $\mathrm{S}$-Twin instrument. EDX analyses of different elements were recorded with the above instrument.

\section{XRD studies}

The lyophilized AgNPs coated on XRD grid were subjected to XRD analysis under SEIFERT JSO-DEBYEFLEX 2002 model operated at $40 \mathrm{kV}$ and a current of $30 \mathrm{~mA}$ with $\mathrm{Cu} \cdot \mathrm{K} \alpha$ radiation of wavelength $1.5406 \AA$. The XRD pattern was scanned in the $2 \theta$ range from $30^{\circ}$ to $70^{\circ}$ with a step size of $0.04 \%$ s.

\section{Fourier transform infrared spectroscopy}

FTIR spectra of the aqueous leaf extract and AgNPs samples were analyzed by FTIR spectroscopy (Hitachi Ltd., Tokyo, Japan). The FTIR analysis was performed with $\mathrm{KBr}$ pellets and recorded in the range of $400-4,000 \mathrm{~cm}^{-1}$. The various modes of vibrations were identified and assigned to determine the different functional groups present in the samples.

\section{Antibacterial efficiency of biosynthesized AgNPs}

The synthesized AgNPs obtained from the leaf extract of $C$. roxburghii was tested for its antibacterial potent against Gram-positive bacteria, such as Bacillus subtilis,
Staphylococcus aureus, and Micrococcus luteus, and Gram-negative bacteria, such as Pseudomonas aeruginosa, Escherichia coli, and Enterobacter aerogenes. The antibacterial activities of the sample were determined by following the agar plate well diffusion method ${ }^{21}$ using $30 \mathrm{~mL}$ of Mueller Hinton agar medium in sterilized Petri plates. The agar plates were seeded with freshly prepared different pathogens. Agar wells with diameter of $6 \mathrm{~mm}$ were made with the help of a sterile stainless steel cork borer. The wells were labeled as A, B, C, and D. The wells A and B were loaded with $40 \mu \mathrm{L}$ of the biosynthesized $\mathrm{AgNPs}$ and $\mathrm{AgNO}_{3}(1 \mathrm{mM})$; C well was loaded with $40 \mu \mathrm{L}$ containing $10 \mu \mathrm{g}$ of the streptomycin. The D well was loaded with $40 \mu \mathrm{L}$ of the aqueous leaf extract of $C$. roxburghii. The plates were incubated at $37^{\circ} \mathrm{C}$ for 24 hours, and the zone of inhibition (ZOI; mm) appearing around the wells was recorded.

\section{Minimum inhibitory concentration}

The microbial activity of AgNPs was recorded by the determination of minimum inhibitory concentration (MIC). The selected six different bacterial suspensions were prepared and seeded on the agar medium. Then $10 \mu \mathrm{L}, 20 \mu \mathrm{L}, 30 \mu \mathrm{L}$, and $40 \mu \mathrm{L}$ of AgNPs were loaded to the respective wells. All the plates were incubated at $37^{\circ} \mathrm{C}$ for 24 hours, and the MIC concentration was recorded.

\section{Antimicrobial activity of AgNPs loaded on cotton fabrics and SEM studies}

The respective MIC concentration of AgNPs of the pathogens was added on the pre-sterilized white cotton cloth of $1 \mathrm{~cm}^{2}$ under aseptic condition and tested against the six different pathogenic bacteria. The cloth was then placed in a sterile container and kept at $50^{\circ} \mathrm{C}$ for overnight to evaporate the water content. Then the pathogens, such as B. subtilis, $S$. aureus, M. luteus, P. aeruginosa, E. coli, and E. aerogenes, were seeded uniformly on the respective plates and placed on the cotton cloth impregnated with AgNPs. The plates were then incubated at $37^{\circ} \mathrm{C}$ for 24 hours, and the ZOI was recorded. Concurrently, the cotton cloth impregnated with AgNPs was also observed under scanning electron microscopy Hitachi S-3400N.

\section{Results and discussion UV-visible spectroscopy}

C. roxburghii leaf (Figure 1) aqueous extract added with silver nitrate at $1 \mathrm{mM}$ showed a change in color from pale yellow to dark brown (Figure 2). This was due to the excitation of surface plasmon resonance (SPR) by 


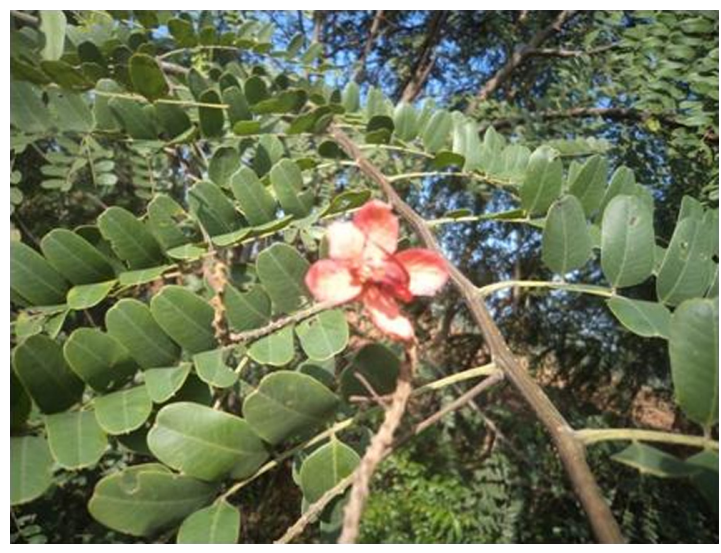

Figure I C. roxburghii plant leaves.

Abbreviation: C. roxburghii, Cassia roxburghii.

AgNPs. ${ }^{22}$ AgNPs have free electrons, which give rise to SPR absorption band, due to the combined vibration of electrons of metal nanoparticles in resonance with the light wave. ${ }^{23}$ The reduction of AgNPs in the aqueous solution of silver complex during the reaction with the leaf extract of C. roxburghii was confirmed by the UV-visible spectra. Absorption spectra of AgNPs at $430 \mathrm{~nm}$ after 24 hours of incubation sharpening of peak indicated that the particles are found monodispersed. The $\mathrm{AgNO}_{3}$ solution and C. roxburghii leaf aqueous extract alone did not show any peak between $300 \mathrm{~nm}$ and $700 \mathrm{~nm}$ (Figure 3).

\section{Stability of silver nanoparticles}

Time

AgNPs synthesis was also evaluated under UV-visible spectroscopy at different durations (0 hour-2 months) in order to study the stability of the formed nanoparticles. It was recorded that with increased contact time, the peak

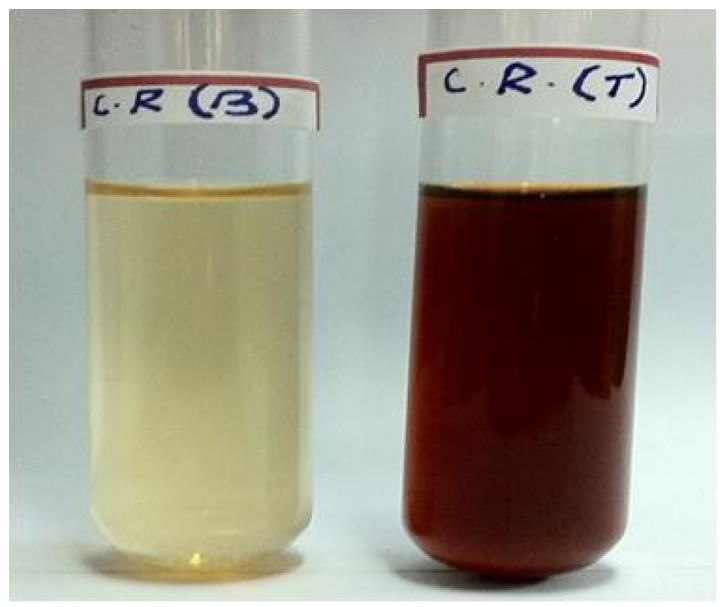

Figure 2 Optical photographs of synthesized AgNPs from C. roxburghii. Abbreviations: AgNPs, silver nanoparticles; C. R., C. roxburghii; B, blank; T, test; C. roxburghii, Cassia roxburghii.

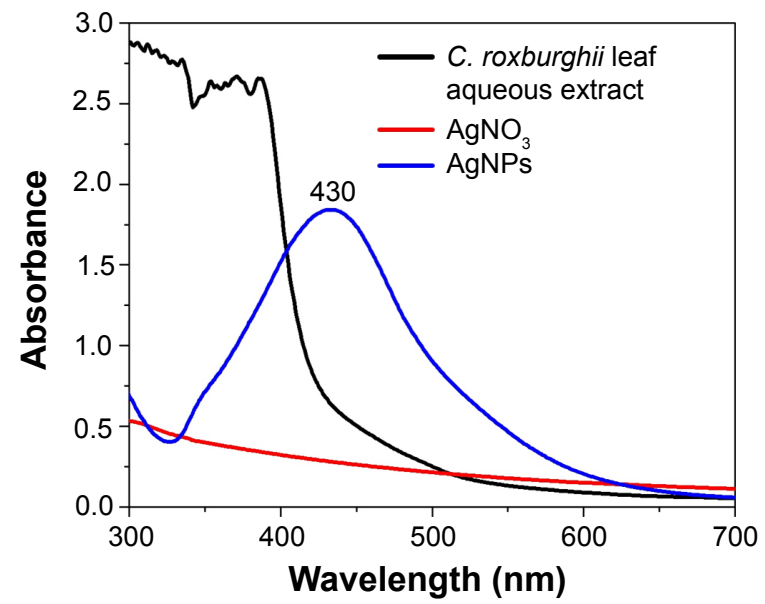

Figure 3 UV-visible spectrum of the AgNPs synthesized from C. roxburghii. Abbreviations: AgNPs, silver nanoparticles; C. roxburghii, Cassia roxburghii; $\mathrm{AgNO}_{3}$, silver nitrate.

becomes sharper. The reaction had started within 6 hours, and the SPR showed a peak at $420 \mathrm{~nm}$. Thereafter, there was a shift in the peak from $426 \mathrm{~nm}$ at 12 hours and $428 \mathrm{~nm}$ at 18 hours. The reaction ended at 24 hours with an absorption peak at $430 \mathrm{~nm}$, and the two-month old sample also exhibited a peak at $430 \mathrm{~nm}$ (Table 1). ${ }^{24}$ The sharper peak indicated the formation of monodisperse nanoparticles from the extract of C. roxburghii. These results showed that there is no alteration in the peak even after 2 months of incubation, thus indicating the higher stability of biosynthesized AgNPs of C. roxburghii (Figure 4).

\section{HR-TEM and EDAX analysis}

Morphology and particle size of AgNPs were characterized using HR-TEM. The HR-TEM images of AgNPs synthesized with the leaf extract of C. roxburghii are shown in Figure 5A and $\mathrm{B}$. The particles are predominantly spherical in shape with a diameter ranging from $10 \mathrm{~nm}$ to $30 \mathrm{~nm}$. The EDAX (Figure 5C) spectrum shows a single signal for silver, indicating that the synthesized AgNPs were free from impurity. The strong signal of the Ag atoms indicated the crystalline

Table I Stability of AgNPs

\begin{tabular}{lll}
\hline Serial no & Hours & Wavelength (nm) \\
\hline I & 0 hrs & 000 \\
2 & 6 hrs & 420 \\
3 & 12 hrs & 426 \\
4 & 18 hrs & 428 \\
5 & 24 hrs & 430 \\
6 & 5 th day & 430 \\
7 & I5th day & 430 \\
8 & I month & 430 \\
9 & 2 months & 430 \\
\hline
\end{tabular}

Abbreviations: AgNPs, silver nanoparticles; hrs, hours. 


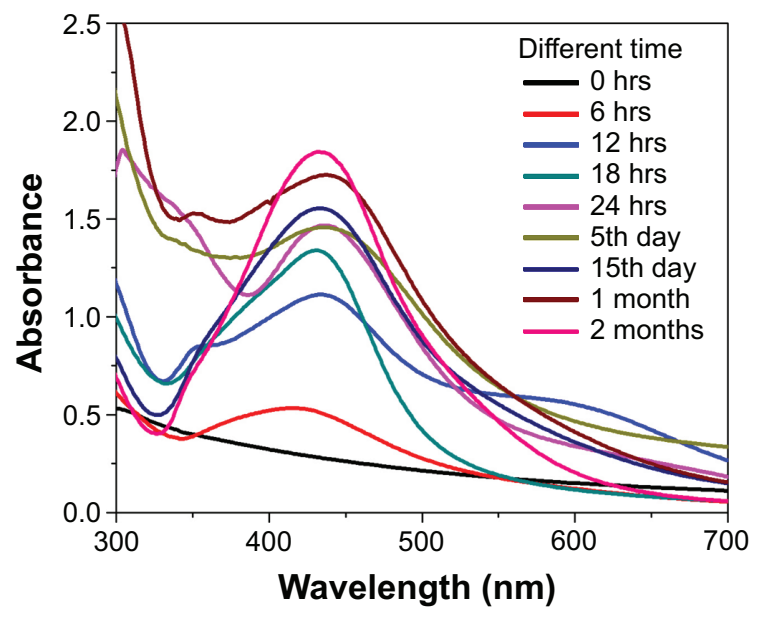

Figure 4 UV-visible spectrum of the AgNPs at different time durations. Abbreviations: AgNPs, silver nanoparticles; hrs, hours. property. The presence of O peaks along with the Ag signals suggested that the AgNPs are capped by phytoconstituents through oxygen atom.

\section{XRD analysis}

The XRD patterns of AgNPs synthesized from the leaf aqueous extract of $C$. roxburghii were assigned to a face-centered cubic ${ }^{25}$ (Figure 6). The Bragg reflections with $2 \theta$ values of $38.1^{\circ}, 44.3^{\circ}$ and $64.4^{\circ}$ corresponded to the (111), (202), and (220) sets of lattice planes, and they may be indexed as the band for face-centered cubic structures of silver. ${ }^{26}$ The XRD pattern, thus, clearly illustrated that the AgNPs synthesized by the present green method are crystalline in nature.
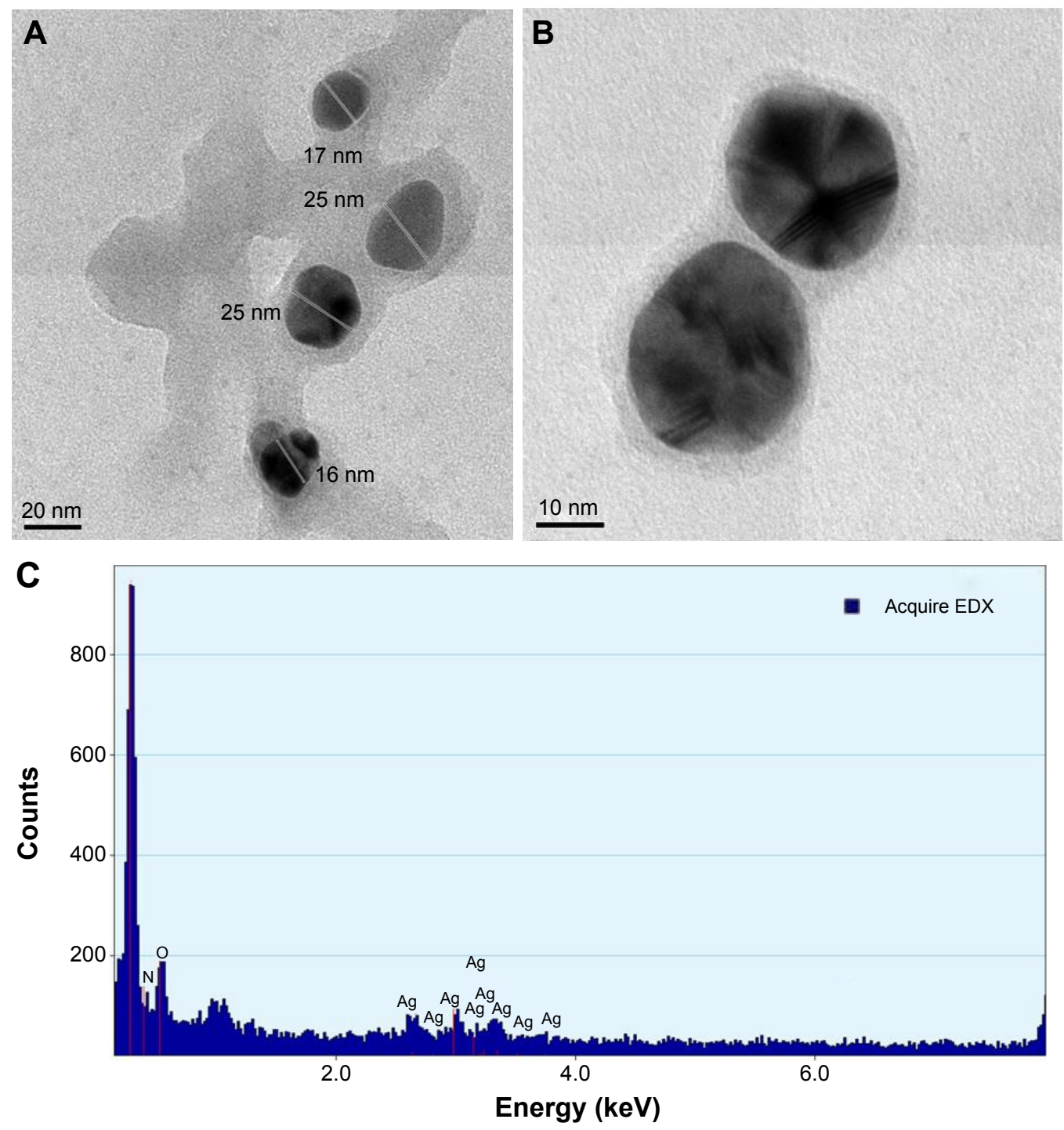

Figure 5 High-resolution transmission electron spectroscopy images of (A) AgNPs (scale bar 20 nm) and (B) magnified AgNPs (scale bar 10 nm). (C) Energy dispersive $X$-ray spectrum of AgNPs.

Abbreviations: AgNPs, silver nanoparticles; EDX, energy dispersive X-ray. 


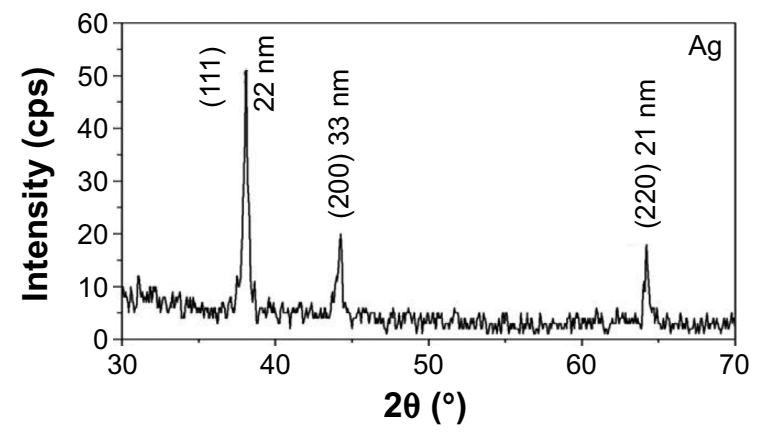

Figure 6 X-ray diffraction pattern of AgNPs synthesized from C. roxburghii. Abbreviations: AgNPs, silver nanoparticles; C. roxburghii, Cassia roxburghii.

\section{Fourier transform infrared spectroscopy}

The FTIR spectrum explains the interaction of AgNPs with leaf biomolecules of $C$. roxburghii. It showed the broadband at $3,422 \mathrm{~cm}^{-1}$ due to the stretching vibrations of $-\mathrm{N}-\mathrm{H}$ and -O-H groups, while an absorption band at 2,920 $\mathrm{cm}^{-1}$ due to $-\mathrm{C}-\mathrm{H}$ group. An absorption band appeared at $1,616 \mathrm{~cm}^{-1}$ due to the stretching vibration of $\mathrm{C}=\mathrm{C}$, while an absorption band at $1,376 \mathrm{~cm}^{-1}$ is due to the presence of $\mathrm{C}$-N-like amine or C-O-like phenol groups. The two absorptions recorded at $1,246 \mathrm{~cm}^{-1}$ and $1,096 \mathrm{~cm}^{-1}$ are due to the presence of $\mathrm{C}-\mathrm{N}$ (aliphatic amine) stretching vibration. The two weak bands at $825 \mathrm{~cm}^{-1}$ and $618 \mathrm{~cm}^{-1}$ are due to the out-of-plane bending vibrations of $-\mathrm{O}-\mathrm{H}$ and $\mathrm{C}-\mathrm{H}$ groups, respectively. The FTIR results confirmed the presence of $-\mathrm{NH},-\mathrm{OH}, \mathrm{C}=\mathrm{C}$, and $\mathrm{CH}$ groups, which indicated that the plant extract containing the hydroxyl and amine groups substituted flavonoids (Figure 7A). The FTIR spectrum of the extract-AgNPs (Figure 7B) also exhibited similar FTIR spectral values, but the stretching vibration band at $1,377 \mathrm{~cm}^{-1}$ corresponds to the $\mathrm{C}-\mathrm{N}$ stretching vibrations peak was blend, which is amine group peak. ${ }^{27}$ The peaks recorded at $1,376 \mathrm{~cm}^{-1}$ of the aqueous extract of $C$. roxburghii expressed in AgNPs indicated that the amino groups are partially utilized for the encapsulation and stabilization of AgNPs. Further, it is observed that the flavonoids ${ }^{28}$ act as a reducing agent, which reduces $\mathrm{Ag}^{+}$to $\mathrm{Ag}^{0}$ and the amino group as a stabilizing agent in the green synthesis of AgNPs. Thus, the FTIR study reveals the multifunctionality of the aqueous extract of C. roxburghii where reduction and stabilization occur simultaneously.

\section{Antibacterial activity of AgNPs and MIC}

Biosynthesized AgNPs were studied for their antibacterial activity against three different Gram-negative and three Gram-positive pathogenic bacteria by following standard method, and ZOI was recorded..$^{29}$ Among the pathogens,
$P$. aeruginosa was highly sensitive to the biologically synthesized nanoparticles, $21 \mathrm{~mm}$ ZOI; followed by M. luteus of $19 \mathrm{~mm}$; E. aerogenes of $18 \mathrm{~mm}$; B. subtilis of $17 \mathrm{~mm}$; E. coli of $16 \mathrm{~mm}$; and $S$. aureus of $12 \mathrm{~mm}$. $\mathrm{AgNO}_{3}$ alone showed least activity. The aqueous extract of $C$. roxburghii did not show any inhibitory activity against the tested pathogens, whereas streptomycin showed high antibacterial activity than synthesized AgNPs (Figure 8, Table 2). The MIC of $7.2 \mu \mathrm{g} / \mathrm{mL}$ against $P$. aeruginosa was followed by $8.8 \mu \mathrm{g} / \mathrm{mL}$ against $M$. luteus. However, the MIC toward $S$. aureus was only $12.4 \mu \mathrm{g} / \mathrm{mL}$ (Table 3). Modern times have witnessed many potential biomedical applications of nanobiotechnology. Nanoparticles, for instance, have immense applications in the early diagnosis and management of diseases, including those caused by emerging multidrug-resistant pathogens. AgNPs have found wide usage in various industries, and they are known to inhibit a number of microorganisms. AgNPs are extensively used in the pharmaceutical and medical industries as they have shown inhibitory activities against various microorganisms. They have also been used in balms, topical ointments to avert infections following burn wounds. ${ }^{30,31}$ AgNPs can easily reach the nuclear content of bacteria, and as they are present in the greatest surface area, therefore, the contact with bacteria is the greatest. ${ }^{32}$ This could be the reason why they showed high antibacterial activity. ${ }^{33,34}$

\section{Antimicrobial activity of AgNPs loaded on cotton fabrics and SEM studies}

The AgNPs impregnated on cotton fabrics were tested against three different Gram-positive bacteria and three Gram-negative bacteria, and ZOI was recorded. The cotton fabrics without AgNPs (Figure 9A) with AgNPs observed under SEM revealed the distribution of AgNPs in Figure 9B and C. The efficacy of fabrics with AgNPs against pathogens is given in Figure 10B. ${ }^{35}$ The cotton fabrics without AgNPs did not show any antibacterial activity (Figure 10A). AgNPs-immobilized cotton cloth could find wide application in various fields. In hospitals, it could be used by medical practitioners as self-sterilizing coat or apron material since the practitioners are constantly exposed to pathogenic organisms, which are potent causes of series side effects. The cotton cloth immobilized with AgNPs can also be used as an antiseptic bandage material for wound dressing. ${ }^{36}$ Lee et al reported the antibacterial effect of the AgNPs-immobilized cloth material against Gram-positive, Gram-negative, and antibiotic-resistant bacteria. ${ }^{36}$ Skin-irritation tests of the AgNPs-immobilized cloth material on guinea pigs revealed 
A

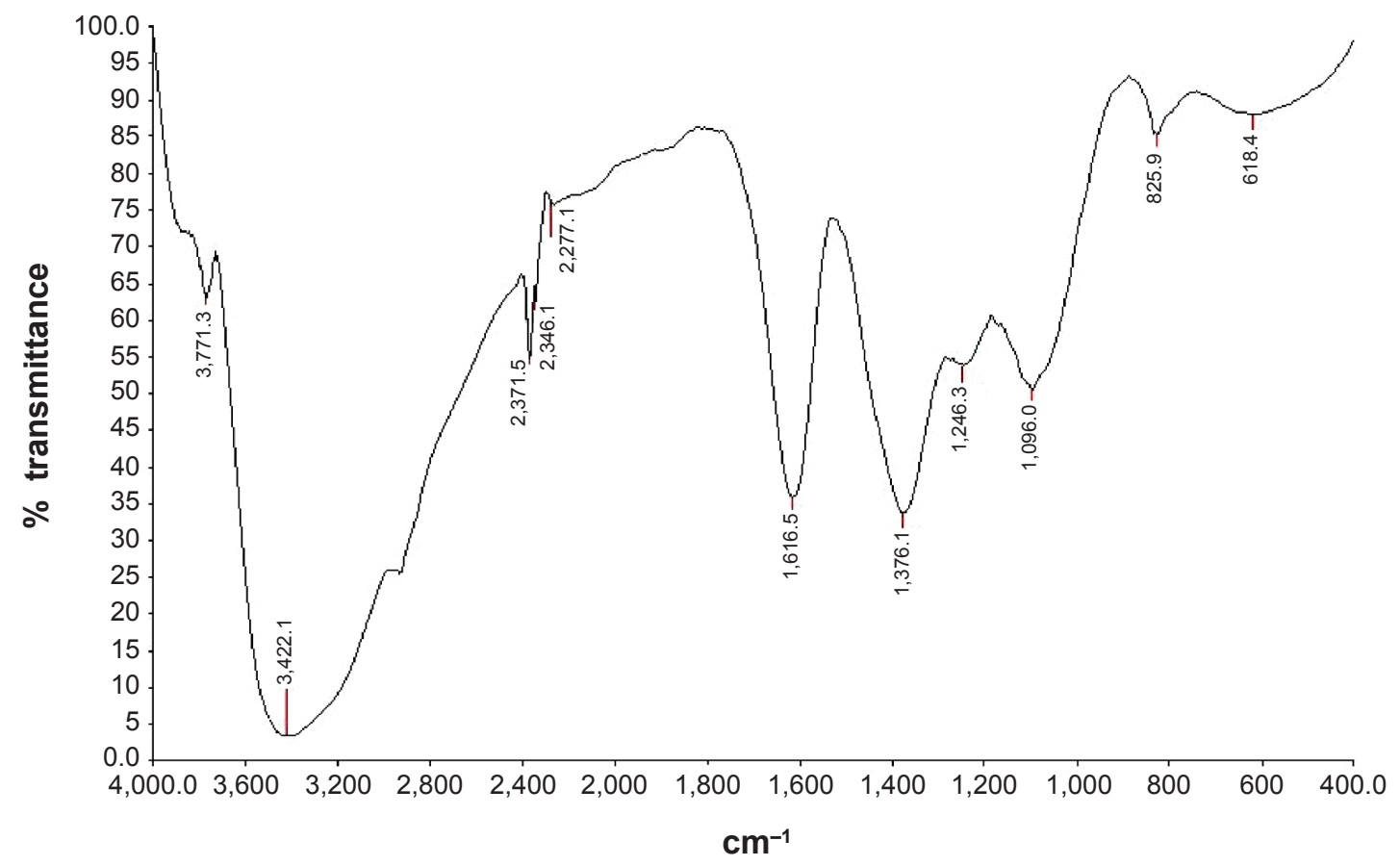

B

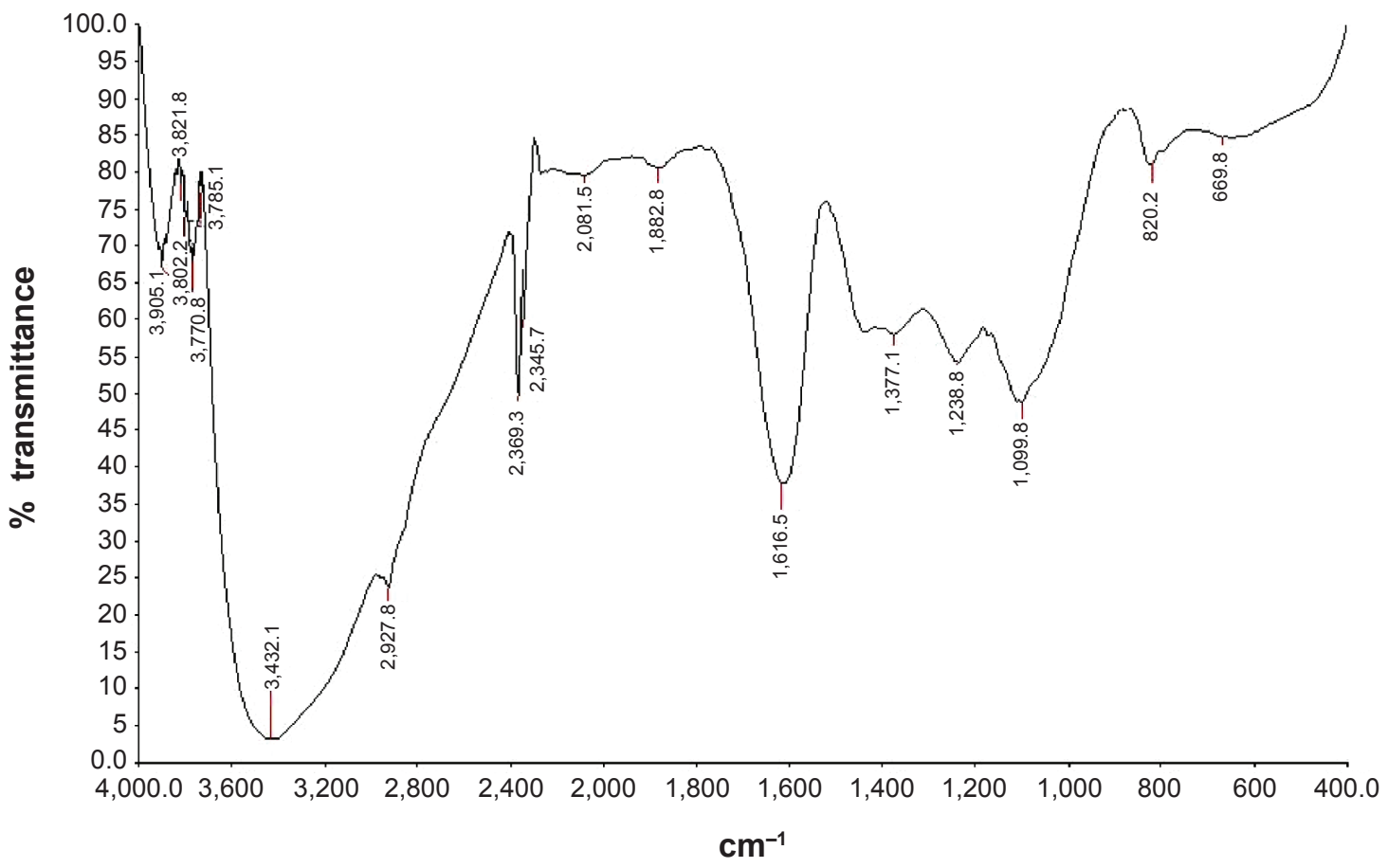

Figure 7 Fourier transform infrared spectrum of $(\mathbf{A})$ C. roxburghii leaf aqueous extract and (B) AgNPs.

Abbreviations: AgNPs, silver nanoparticles; C. roxburghii, Cassia roxburghii.

no side effects. ${ }^{36}$ Interaction of AgNPs with human fibroblasts affected their fission, but it was not toxic. ${ }^{37}$ Though AgNPs are reported to cause no big health problems when administered into the body, argyria is always a problem, irrespective of the nanosize of silver. ${ }^{38}$ In daily life, AgNPs-impregnated clothing may find a good applicability in underwear and socks. ${ }^{36}$ However, further studies are required to verify if the bacteria develop resistance toward the nanoparticles and associated cytotoxicity ${ }^{39}$ of nanoparticles toward human cells before proposing their therapeutic use. 

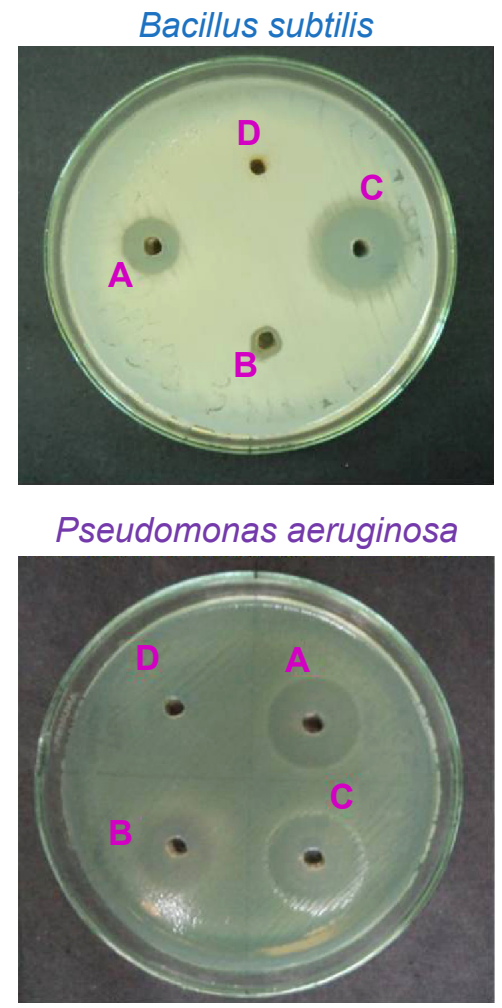

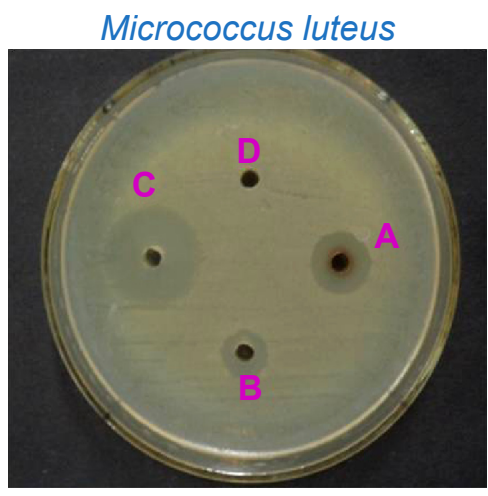

Enterobacter aerogenes

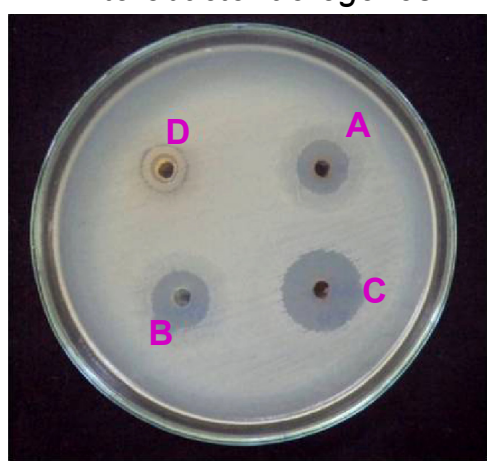

Staphylococcus aureus

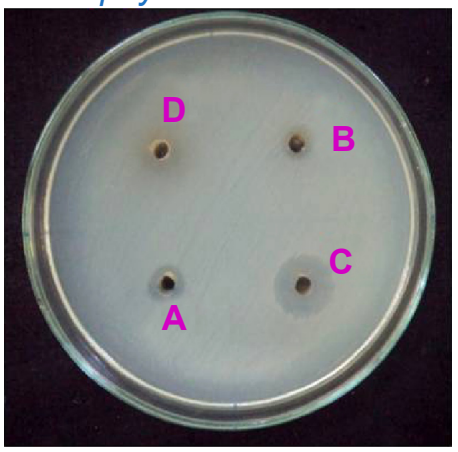

Escherichia coli

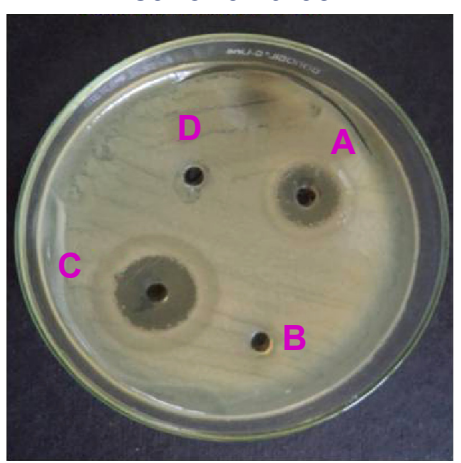

Figure 8 Antibacterial activity of AgNPs synthesized from C. roxburghii.

Notes: (A) biologically synthesized AgNPs, (B) silver nitrate, (C) streptomycin, (D) plant leaf aqueous extract. Abbreviations: AgNPs, silver nanoparticles; C. roxburghii, Cassia roxburghii.
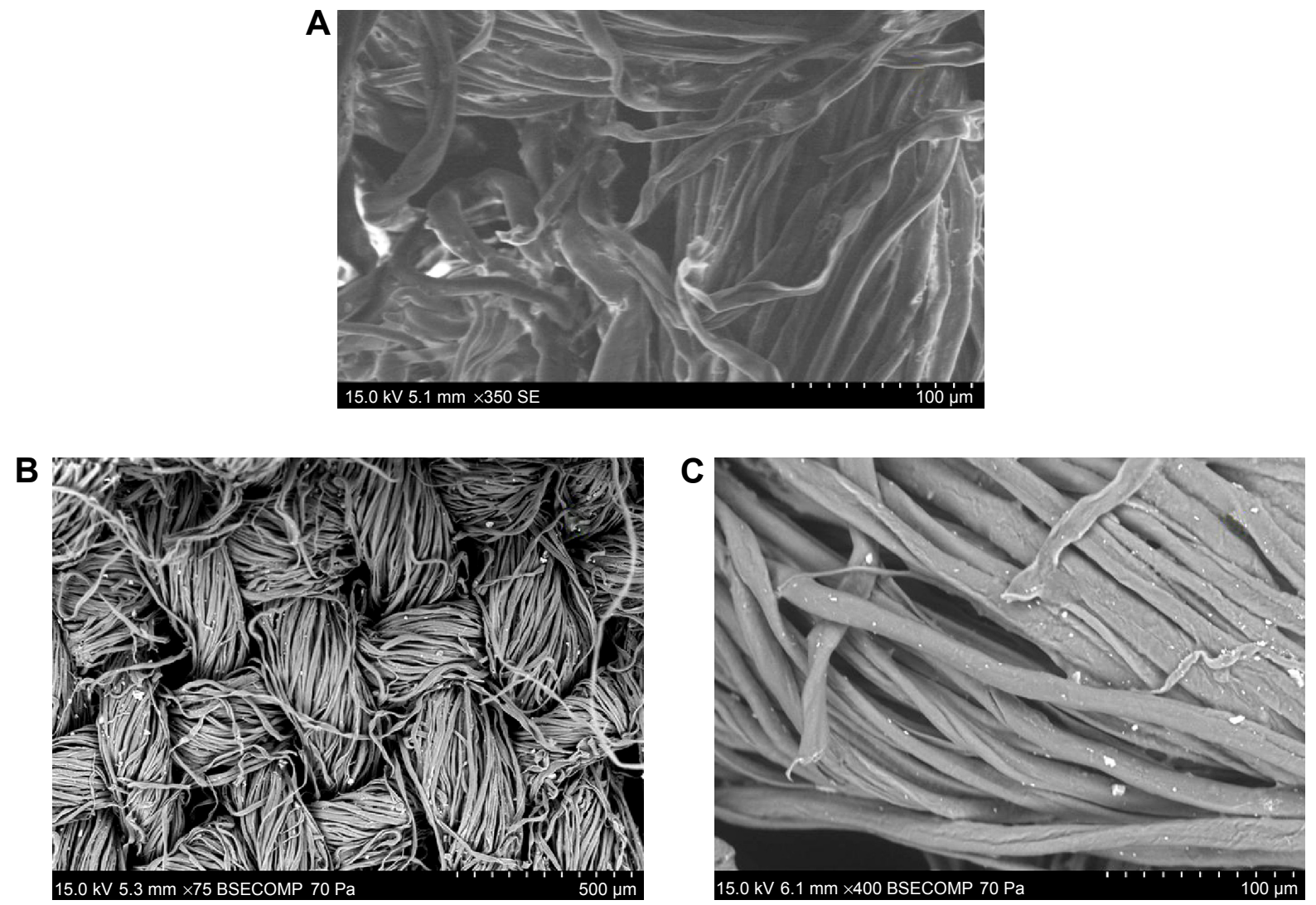

Figure 9 SEM images of the cotton fabric.

Notes: (A) Without AgNPs (control) (scale bar $100 \mu \mathrm{m}$ ). (B) Containing AgNPs (scale bar $500 \mu \mathrm{m}$ ). (C) Containing AgNPs (scale bar I00 $\mu \mathrm{m}$ ).

Abbreviations: SEM, scanning electron microscope; AgNPs, silver nanoparticles. 
Table 2 Antibacterial activity of the AgNPs

\begin{tabular}{lllll}
\hline Name of the organism & \multicolumn{2}{l}{ Zone inhibition (mm in diameter) } & \\
\cline { 2 - 5 } & AgNPs & C. roxburghii aqueous extract & Positive control (streptomycin) & AgNO $_{3}$ \\
\hline Bacillus subtilis & 17 & - & 23 & 8 \\
Micrococcus luteus & 19 & - & 25 & 9 \\
Staphylococcus aureus & 12 & - & 18 & 8 \\
Pseudomonas aeruginosa & 21 & - & 26 & 16 \\
Enterobacter aerogenes & 18 & - & 21 & 12 \\
Escherichia coli & 16 & - & 22 & 8 \\
\hline
\end{tabular}

Abbreviations: $\mathrm{AgNPs}$, silver nanoparticles; $\mathrm{AgNO}_{3}$, silver nitrate; $C$. roxburghii, Cassia roxburghii.

Table 3 Minimum inhibition concentration of AgNPs

\begin{tabular}{lll}
\hline Bacteria & Zone of inhibition $(\mathbf{m m})$ & MIC $(\mu \mathbf{g} / \mathbf{m L})$ \\
\hline Bacillus subtilis & 17 & 9.2 \\
Micrococcus luteus & 19 & 8.8 \\
Staphylococcus aureus & 12 & 12.4 \\
Pseudomonas aeruginosa & 21 & 7.2 \\
Enterobacter aerogenes & 18 & 8.3 \\
Escherichia coli & 16 & 9.8 \\
\hline
\end{tabular}

Abbreviations: AgNPs, silver nanoparticles; MIC, minimum inhibitory concentration.
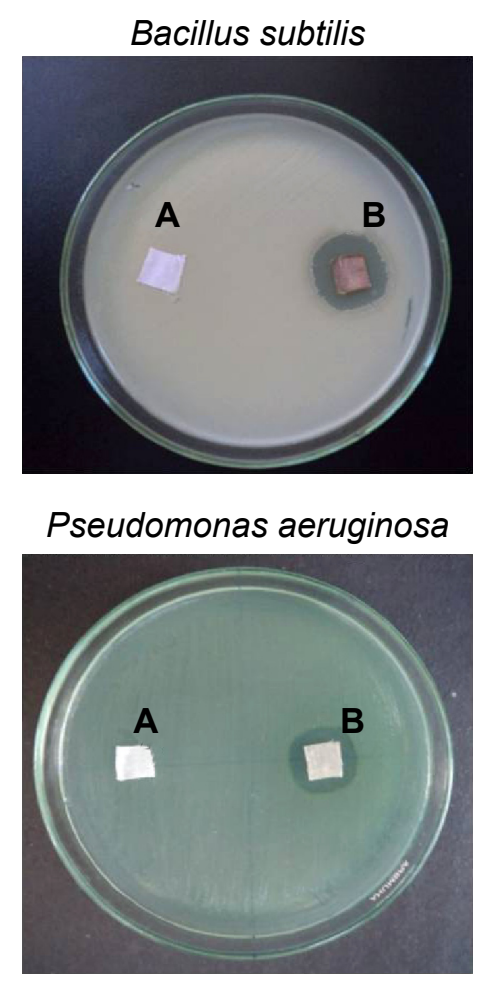
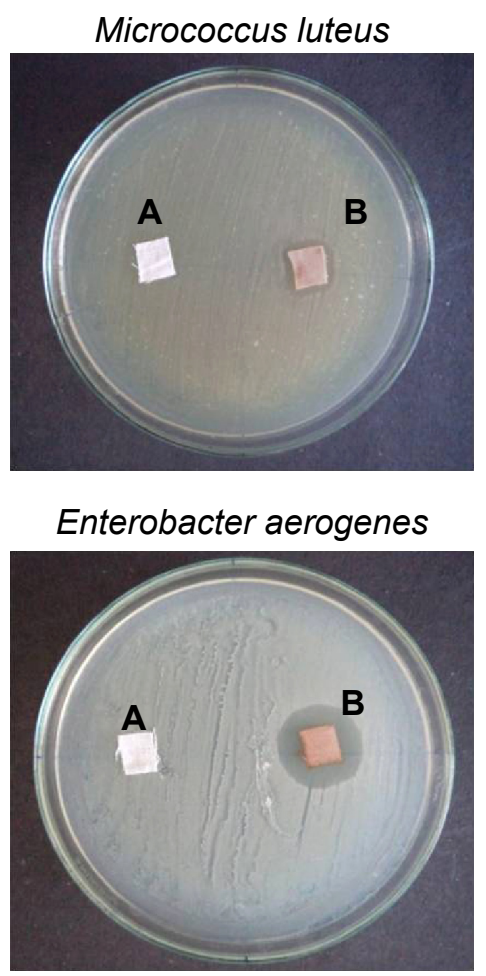
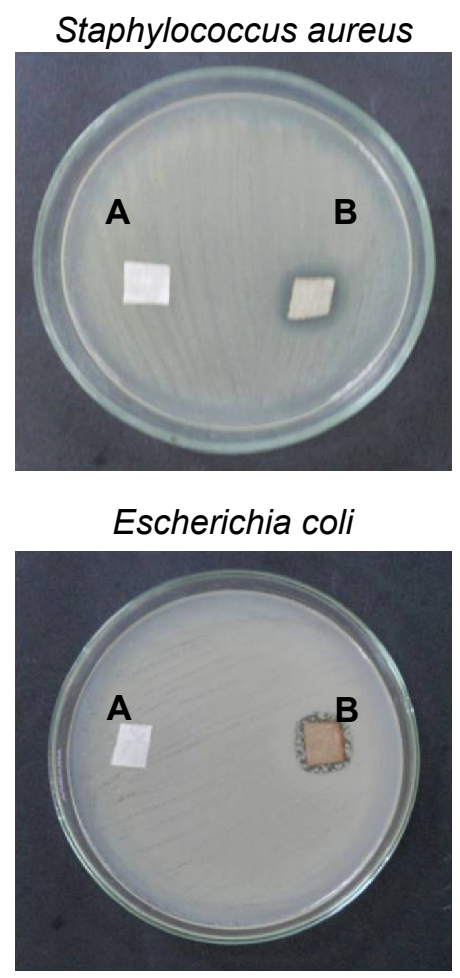

Figure 10 Antibacterial activity of AgNPs coated on cotton fabric.

Notes: (A) Without loaded AgNPs (control). (B) AgNPs loaded on cotton fabric (test).

Abbreviations: AgNPs, silver nanoparticles; C. roxburghii, Cassia roxburghii. 


\section{Conclusion}

AgNPs were green synthesized using the leaf biomolecules of $C$. roxburghii. We demonstrated the possibility of using biologically synthesized AgNPs and their incorporation in cotton materials. The cotton fabrics incorporated with the AgNPs exhibited antibacterial activity against both Gram-positive and Gram-negative bacteria. Considering the observation from UV-visible absorption, stability, XRD, HR-TEM of the C. roxburghii synthesized AgNPs, the impregnated AgNPs on cotton fabric could play a vital role in biomedical application since it is pollutant free and eco-friendly.

\section{Acknowledgments}

The authors wish to thank Prof R Rengasamy, Director, Centre for Advanced Studies in Botany, University of Madras, Chennai, for providing the laboratory facilities. They also thank National Center for Nanoscience and Nanotechnology, University of Madras, for providing instrumentation facility and UGC herbal science scheme Delhi, for financial support.

\section{Disclosure}

The authors report no conflicts of interest in this work.

\section{References}

1. Xiujuan H, Xiao Y, Wei Z, Meidong L. In-situ formation of silver nanoparticles stabilized by amphiphilic star-shaped copolymer and their catalytic application. Appl Surf Sci. 2012;258:2655-2660.

2. Das SK, Khan MM, Guha AK, Das AR, Mandal AB. Silver-nano biohybride material: synthesis, characterization and application in water purification. Bioresour Technol. 2012;124:495-499.

3. Pankaj Kumar R, Vellaichamy G, Krishnamoorthi S. Microwave assisted polymer stabilized synthesis of silver nanoparticles and its application in the degradation of environmental pollutants. Mater Sci Eng B. 2012;177:456-461.

4. Costa C, Conte A, Buonocore GG, Del Nobile MA. Antimicrobial silver-montmorillonite nanoparticles to prolong the shelf life of fresh fruit salad. Int J Food Microbiol. 2011;148:164-167.

5. de Moura MR, Mattoso LHC, Zucolotto V. Development of cellulosebased bactericidal nanocomposites containing silver nanoparticles and their use as active food packaging. J Food Eng. 2012;109:520-524.

6. Vesna I, Zoran S, Vesna V, et al. The influence of silver content on antimicrobial activity and color of cotton fabrics functionalized with Ag nanoparticle. Carbohydr Polym. 2009;78:564-569.

7. Majid M, Farbod A, Ali S, Mohammad Karim R. Durable antibacterial and cross-linking cotton with colloidal silver nanoparticles and butane tetracarboxylic acid without yellowing. Colloids Surf B Biointerfaces. 2012;89:196-202.

8. Chen W, Cai W, Zhang L, Wang G. Sonochemical processes and formation of gold nanoparticles within pores of mesoporous silica. J Colloid Interface Sci. 2001;238:291-295.

9. Frattini A, Pellegri N, Nicastro D, Sanctis O. Preparation of amine coated silver nanoparticles using triethylenetetramine. Mater Chem Phys. 2005;94:148-152.

10. Goodsell DS. Bionanotechnology: Lessons from Nature. Hoboken: Wiley; 2004.
11. Sathishkumar M, Sneha K, Won SW, Cho CWS, Yun YS. Cinnamon zeylanicum bark extract and powder mediated green synthesis of nanocrystalline silver particles and its bactericidal activity. Colloids Surf B Biointerfaces. 2009;73:332-338.

12. Rogers JV, Parkinson CV, Choi YW, Speshock JL, Hussain SM. A preliminary assessment of silver nanoparticle inhibition of monkeypox virus plaque formation. Nanoscale Res Lett. 2008;3:129-133.

13. Panacek A, Kolar M, Vecerova R, et al. Antifungal activity of silver nanoparticles against Candida spp. Biomaterials. 2009;30:6333-6340.

14. Impellitteri CA, Tolaymat TM, Scheckel KG. The speciation of silver nanoparticles in antimicrobial fabric before and after exposure to a hypochlorite detergent solution. J Environ Qual. 2009;38:1528-1530.

15. Panyala NR, Pena-Mendez EM, Havel J. Silver or silver nanoparticles: a hazardous threat to the environment and human health. J Appl Biomed. 2008;6:117-129.

16. Navarro E, Baun A, Behra R, et al. Environmental behaviour and ecotoxicity of engineered nanoparticles to algae, plants and fungi. Ecotoxicology. 2008; 17:372-386.

17. Ma X, Geiser-Lee J, Deng Y, Kolmakov A. Interactions between engineered nanoparticles (ENPs) and plants: phytotoxicity, uptake and accumulation. Sci Total Environ. 2010;408:3053-3061.

18. Lin D, Xing B. Phytotoxicity of nanoparticles: inhibition of seed germination and root growth. Environ Pollut. 2007;150:243-250.

19. Arulkumaran KS, Rajasekaran A, Ramasamy A, Jegadee-san M, Kavimani S, Somasundaram A. Cassia roxburghii seeds protect liver against toxic effects of ethanol and carbontetrachloride in rats. Int J Pharm Tech Res. 2009;1(2):246-273.

20. Srinivas KR, Gnananath K, Sanjeeva AK, Vinay D, Krishna B. Evaluation of in vivo wound healing potential of Cassia roxburghii leaves extracts. Der Pharm Sin. 2011;2(6):32-38.

21. Perez C, Paul M, Bazerque P. An antibiotic assay by the agar well diffusion method. Acta Biol Med Exp. 1990;15:113-115.

22. Ponarulselvam S, Panneerselvam C, Murugan K, Aarthi N, Kalimuthu K, Thangamani S. Synthesis of silver nanoparticles using leaves of Catharanthus roseus and their antiplasmodial activities. Asain Pac J Trop Biomed. 2012;2(7):574-580.

23. Manopriya M, Karunaiselvi B, John Paul JA. Green synthesis of silver nanoparticles from the leaf extracts of Euphorbia hirta and Nerium indicum. J Nanomater Biostruct. 2011;6:869-877.

24. Krishnaraj C, Ramachandran R, Mohan K, Kalaichelvan PT. Optimization for rapid synthesis of silver nanoparticles and its effect on phytopathogenic fungi. Spectrochim Acta A. 2012;93:95-99.

25. Shameli K, Ahmad MB, Jazayeri SD, et al. Investigation of antibacterial properties silver nanoparticles prepared via green method. Chem Cent J. 2012;6:73.

26. Ahmad MB, Shameli K, Darroudi M, Wan Yunus WMZ, Ibrahim NA. Synthesis and characterization of silver/clay nanocomposites by chemical reduction method. Am J Appl Sci. 2009;6:1909-1914.

27. Badri Narayanan K, Sakthivel N. Coriander leaf mediated biosynthesis of gold nanoparticles. Mater Lett. 2008;62:4588-4590.

28. Prathnaa TC, Chandrasekarana N, Raichurb AM, Mukherjee A. Biomimetic synthesis of silver nanoparticles by Citrus limon (lemon) aqueous extract and theoretical prediction of particle size. Colloids Surf B Biointerfaces. 2011;82:152-159.

29. Patil BM, Hooli AA. Green synthesis of silver nanoparticles by Duranta repens leaves and their antimicrobial efficacy. Nanotrends. 2013;14(1): 13-18.

30. Arunachalam KD, Annamalai S, Hari S. One-step green synthesis and characterization of leaf extract-mediated biocompatible silver and gold nanoparticles from Memecylon umbellatum. Int J Nanomedicine. 2013; 8:1307-1315

31. Kasi M, Balakrishnan S, Duraisamy S, Al-Sohaibani S. Biosynthesis of silver nanoparticles using Acacia leucophloea extract and their antibacterial activity. Int J Nanomedicine. 2014;9:2431-2438.

32. Lok CM, Ho CM, Chen R, et al. Proteomic analysis of the mode of antibacterial action of silver nanoparticles. J Proteome Res. 2006;5: 916-924. 
33. Morones JR, Elechiguerra JL, Camacho A. The bactericidal effect of silver nanoparticles. Nanotechnology. 2005;16:2346-2353.

34. Shameli K, Ahmad MB, Zargar M, Yunus WM, Ibrahim NA. Fabrication of silver nanoparticles doped in the zeolite framework and antibacterial activity. Int J Nanomedicine. 2011;6:331-341.

35. Durán N, Marcato PD, Alves OL, et al. Antibacterial effect of silver nanoparticles produced by fungal process on textile fabrics and their effluent treatment. J Biomed Nanotechnol. 2007;3:203-208.

36. Lee HY, Park HK, Lee YM, Kim K, Park SB. A practical procedure for producing silver nanocoated fabric and its antibacterial evaluation for biomedical applications. Chem Commun. 2007;28:2959-2961.
37. Wen HC, Lin YN, Jian SR, et al. Observation of growth of human fibroblasts on silver nanoparticles. J Phys Conf Ser. 2007;61:445-449.

38. Chen X, Schluesener HJ. Nanosilver: a nanoproduct in medical application. Toxicol Lett. 2008;176:1-12.

39. Braydich SL, Hussain S, Schlager JJ, Hofmann MC. In vitro cytotoxicity of nanoparticles in mammalian germline stem cells. Toxicol Sci. 2005;88:412-419.
International Journal of Nanomedicine

\section{Publish your work in this journal}

The International Journal of Nanomedicine is an international, peerreviewed journal focusing on the application of nanotechnology in diagnostics, therapeutics, and drug delivery systems throughout the biomedical field. This journal is indexed on PubMed Central, MedLine, CAS, SciSearch ${ }^{\circledR}$, Current Contents ${ }^{\circledR} /$ Clinical Medicine,

\section{Dovepress}

Journal Citation Reports/Science Edition, EMBase, Scopus and the Elsevier Bibliographic databases. The manuscript management system is completely online and includes a very quick and fair peer-review system, which is all easy to use. Visit http://www.dovepress.com/ testimonials.php to read real quotes from published authors.

Submit your manuscript here: http://www.dovepress.com/international-journal-of-nanomedicine-journal 